\title{
A unique case of systemic thromboembolism in a patient with arrhythmogenic right ventricular cardiomyopathy
}

\author{
Olgierd Wozniak, Marek Konka, Elzbieta K. Biernacka \\ Department of Congenital Heart Diseases, Institute of Cardiology, Warsaw, Poland
}

Postep Kardiol Inter 2015; 11, 1 (39): 67-68 DOI: $10.5114 /$ pwki.2015.49191

\begin{abstract}
A bstract
We report a case of a 37-year-old woman with arrhythmogenic right ventricular cardiomyopathy (ARVC), after implantation of a cardioverter-defibrillator (ICD), who was admitted to our hospital because of focal infarctions in the right kidney and in the spleen. Echocardiography showed thrombi on the ICD electrode and the presence of patent foramen ovale. Patent foramen ovale was successfully closed by septal occluder. To our knowledge it is the first ever case report of paradoxical thromboembolism in a patient with ARVC.
\end{abstract}

Key words: thrombus, arrhythmogenic right ventricular cardiomyopathy, arrhythmogenic right ventricular cardiomyopathy.

A 37-year-old woman with arrhythmogenic right ventricular cardiomyopathy (ARVC), after implantation of a cardioverter-defibrillator (ICD) in 2007 due to episodes of syncope, with a history of transient ischaemic attack (TIA) in 2011, was admitted to our hospital because of sharp, stabbing pain in the left epigastric area. Computed tomography scan revealed focal infarctions in the right kidney and in the spleen. Standard transthoracic echocardiogra-

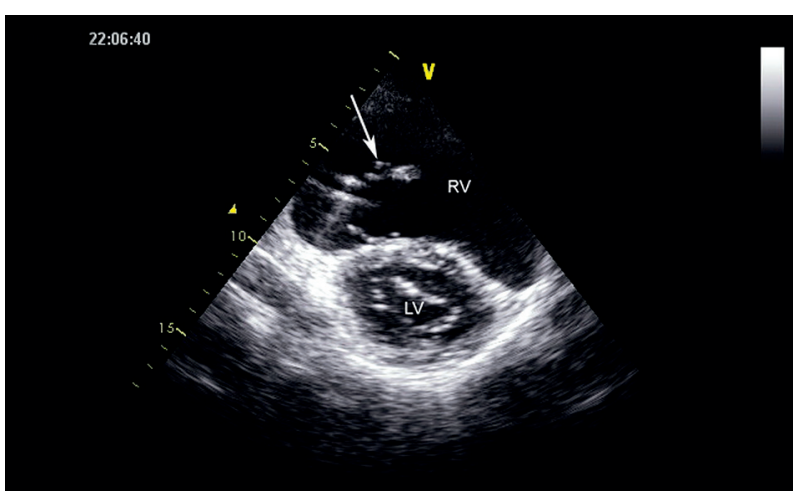

Figure 1. Enlarged right ventricle and ICD electrode (arrow) with thrombi. Transthoracic echocardiogram, parasternal short axis view $R V$ - right ventricle, $L V$ - left ventricle. phy showed significant enlargement of the right ventricle and thrombi on the ICD electrode (Figure 1). In order to determine a mechanism of systemic thromboembolism in a patient with right heart thrombi transoesophageal echocardiography was performed, which revealed a shunt (Figure 2) through the patent foramen ovale (PFO). Valsalva maneuver after agitated saline injection demonstrated right-to-left paradoxical shunting.

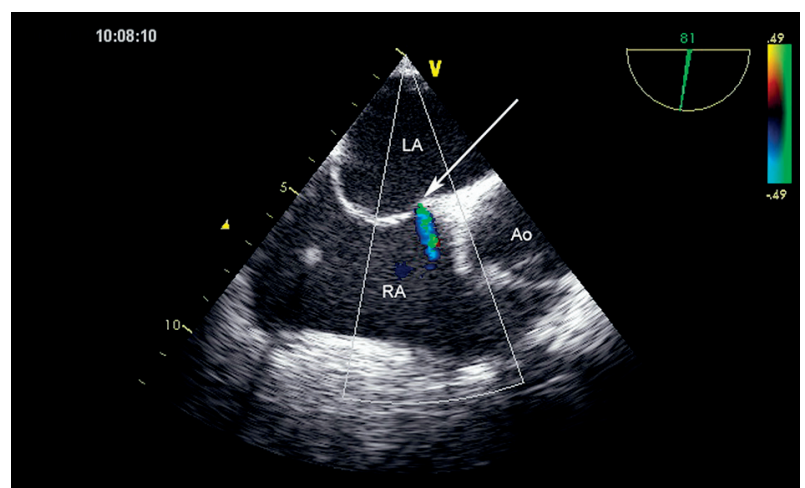

Figure 2. Colour Doppler imaging of the PFO shunt (arrow). Transoesophageal echocardiogram LA - left atrium, RA - right atrium, Ao - aorta.

\section{Corresponding author:}

Olgierd Wozniak MD, Department of Congenital Heart Diseases, Institute of Cardiology, 42 Alpejska St, 04-628 Warsaw, Poland, fax: +48 600233 005, e-mail: owozniak@wp.pl

Received: 14.11.2014, accepted: 8.01.2015. 


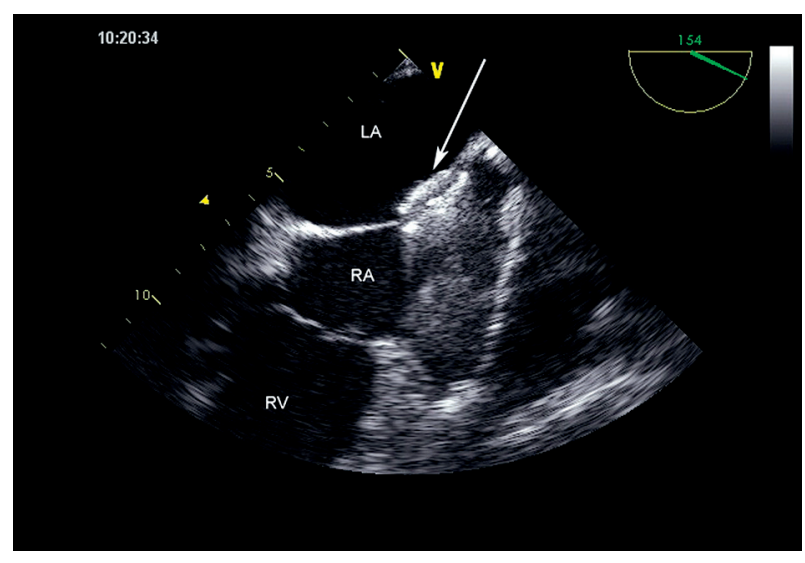

Figure 3. The PFO successfully closed with an Amplatzer Septal Occluder (arrow). Transoesophageal echocardiogram

$R A$ - right atrium, $R V$ - right ventricle, $L A$ - left atrium.

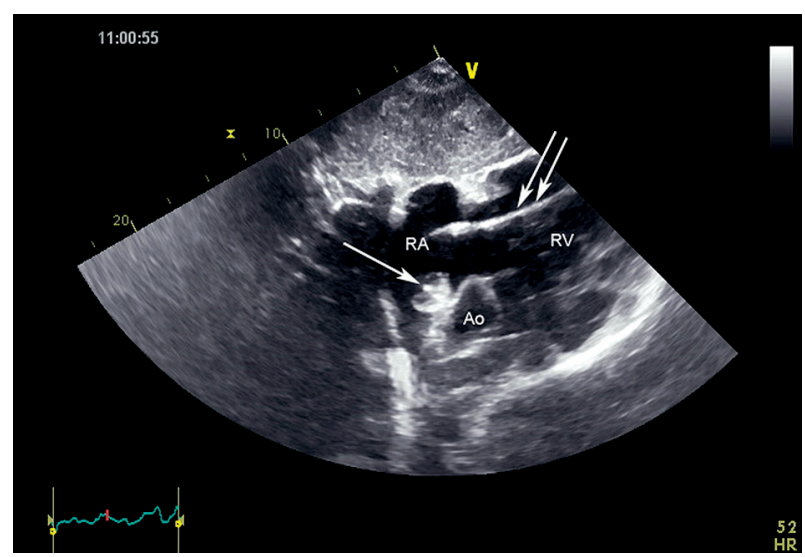

Figure 4. The Amplatzer septal occluder (single arrow) and ICD electrode (double arrow) with thrombi. Transthoracic echocardiogram, substernal view

$R A$ - right atrium, $R V$ - right ventricle, $A o$ - aorta.

In order to prevent further thromboembolic complications the patient was put on aspirin and low molecular weight heparin. Antiphospholipid syndrome and other procoagulant conditions were excluded. Patent foramen ovale was successfully closed by a $25 \mathrm{~mm}$ Amplatzer septal occluder (Figures 3 and 4). In accordance with a regimen of percutaneous PFO treatment, the patient received dual antiplatelet therapy (aspirin and clopidogrel) for 3 months and after this period clopidogrel was discontinued. During the 30 months of follow-up the patient remained uneventful.

In our observation the annual incidence of thromboembolic events in ARVC is $0.5 / 100$ patients [1]. Right ventricle enlargement is one of the factors predisposing to thrombus formation, and anticoagulation should be considered in such patients [2]. In the reported case the right ventricle was very large $(63 \mathrm{~mm})$, but its systolic function was preserved and we decided to continue only with aspirin.

To our knowledge, this is the first case report of paradoxical thromboembolism in a patient with ARVC. In such a scenario percutaneous PFO closure may successfully prevent further complications.

\section{Conflict of interest}

The authors declare no conflict of interest.

\section{References}

1. Wlodarska EK, Wozniak O, Konka M, et al. Thromboembolic complications in patients with arrhythmogenic right ventricular dysplasia/cardiomyopathy. Europace 2006; 8: 596-600.

2. Basso C, Corrado D, Marcus Fl, et al. Arrhythmogenic right ventricular cardiomyopathy. Lancet 2009; 373: 1289-300. 